"torture" will guarantee that these topical issues will be scrutinized by readers.

In a word, Window is a very personal account, on all fronts. The personalities of individual apes are as carefully presented as any cast of characters in a play. Conversations with colleagues, quoted verbatim, convey the excitement of collaborative research in the bush. Again and again, telling vignettes make the point more compellingly than any judiciously qualified generalization could do.

Most importantly, Jane Goodall's viewpoint (and so her personality) have virtually defined our impressions of chimpanzee nature, at least in the Englishspeaking world. This is an awesome responsibility for any scientist.

When Louis Leakey arranged for Jane Goodall to begin studies of the chimpanzees at Gombe, he predicted that it would take ten years to understand them. This seemed excessively cautious at the time. Now, after 30 years, one can only look forward to the next decade of continuing research, and to Goodall's next account of it.

W. C. McGrew is a Reader in the Department of Psychology, University of Stirling, Stirling FK9 4LA, UK

\section{It's a jungle}

\section{Tim Lincoln}

Brazzaville Beach. By William Boyd. Sinclair-Stevenson, London: 1990. £13.95. To be published in the United States early next summer by Morrow.

In this, his fifth novel, William Boyd has returned to home ground, to Africa, for one of the two intertwined stories that make up the narrative. But otherwise the book is a daring and imaginative departure from his previous works. The principal character is a woman, the young and self-assured Hope Clearwater, a botanist turned ethologist, into whose skin Boyd has convincingly written himself (convincingly, that is, as far as a male reader can tell). And the subject matter is mathematics and primatology, with at the bottom of it all the moral that in intellectual endeavours winning, or being seen to win, is everything.

The first story centres on the shadowy figure of John Clearwater, said to be a brilliant mathematician. After four years at Caltech working on game theory, he has returned to Britain, to Imperial College in London, to meet and marry Hope, and to match his brains against the challenge of discovering a simple formulation for turbulence. The second story (chronologically the later) is set in a vaguely defined, war-ravaged part of Africa, at the Grosso Arvore primate research centre. It is there that Hope has gone, after the mental battering unwittingly meted out by her husband, to work under Eugene Mallabar, who has devoted the best part of his life to the study of chimpanzees. Interspersed between the two are brief ruminations, which veer close to the extremes of pretentiousness and profundity, and which in large part come from the present, from Brazzaville Beach, where Hope has eventually washed up. From the

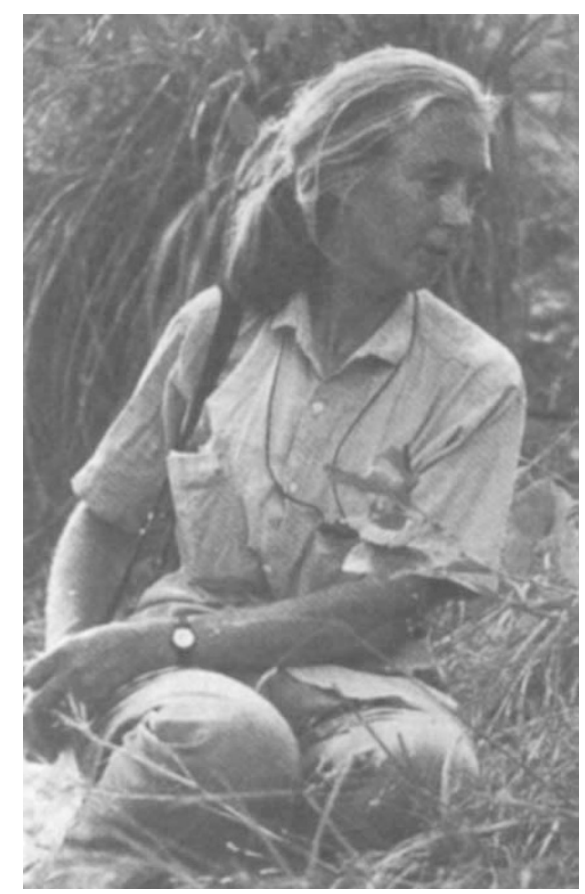

Jane Goodall - inspiration for Hope? (Reproduced from Through a Window*).

beach she examines her life and muses on why her marriage to John Clearwater, and the research at Grosso Arvore, went so badly awry.

Both episodes are narrated in spare and beautifully controlled style. John Clearwater slides into insanity, inch by inch, by way of the fevered digging of holes in search of inspiration, an affair with the wife of an acned physicist, and (towards the end) treatment by electroconvulsive therapy. His agony is to have been on the verge of, but to have been beaten to, what would have been a claim to mathematical immortality in the form of the Clearwater set — a simple algorithm "that would reproduce the magical, infinite variety of the natural world". Life amongst some of the bit players is none too happy either. There is for example Hope's gruesome sister, married to a solicitor and "sinking in the quicksand of prudence, moderation and propriety" in the stuffy respectability of the English home counties.

But it is in Africa, among the chimpanzees, that the starkest of horrors (and the best joke) lie. To followers of the career of Jane Goodall* the chain of events will be

* Jane Goodall's most recent book, Through a Window. My Thirty Years with the Chimpanzees of Gombe, is reviewed on page 371 of this issue. uncannily familiar. Boyd has founded his fiction curiously close to fact, in that for Grosso Arvore one could well read Gombe - not only in the background (research students not merely from the United States but explicitly from Stanford, the evening chore of writing up field notes, the controversial existence of an artificial feeding area, the round of lecture tours), but in the two main occurrences. Of these one is a kidnapping of researchers; the other is a north-south rift in the chimpanzee community, subsequent brutal attacks by the northerners upon the breakaway group, and the shattering observation that chimps are capable of infanticide and cannibalism.

At this point, Boyd parts company with Goodall. In discovering the 'chimpanzee wars', Hope threatens Mallabar's cherished theories, his sources of money and his celebrity status, built in part through his books The Peaceful Primate and Primate's Progress. But experienced operator that he is, the shocking revelations are deftly appropriated as his own. When the third book appears, Hope, like her former husband, has become a loser, literally a footnote to history.

Brazzaville Beach is probably best taken as no more and no less than a compelling novel. Yet, together with other straws in the wind, it is tempting to see in it a sign that one of the two cultures (a matter now widely and wrongly considered passé) is taking the other seriously. That hope is no doubt unfounded. There is, though, the other Hope - William Boyd should persuade himself to get his splendid literary creation off the beach and back into the scientific jungle where she belongs.

Tim Lincoln is News and Views Editor of Nature.

\section{Original lingo?}

\section{John C. Marshall}

Language and Species. by Derek Bickerton. Chicago University Press: 1990. Pp. 297. \$24.95.

BY the close of 1832, the Beagle had reached Tierra del Fuego and was anchored in Good Success Bay. Captain Fitzroy sent a party ashore, and the young Charles Darwin met his first Fuegians in their native habitat. In his diary for 18 December, Darwin wrote: "Their language does not deserve to be called articulate. Capt. Cook says it is like a man clearing his throat; to which may be added another very hoarse man trying to shout and a third encouraging a horse with that peculiar noise which is made in one side of the mouth." Some forty years later, Darwin had the insight (and the courage) 